\title{
O DISCURSO SOBRE SAÚDE NO PROGRAMA "BEM ESTAR" À LUZ DAS CATEGORIAS DE CONSCIÊNCIA POSSÍVEL E CRIAÇÃO CULTURAL
}

\author{
Alan Cesar Dantas Chaves Pombo \\ Secretaria Municipal De Educação Do Rio De Janeiro, Rio de Janeiro, Rio de Janeiro, Brasil \\ André Malina \\ Universidade Federal do Rio de Janeiro, Rio de Janeiro, Rio de Janeiro, Brasil. \\ Ângela Celeste Barreto De Azevedo \\ Universidade Federal do Rio de Janeiro, Rio de Janeiro, Rio de Janeiro, Brasil.
}

\begin{abstract}
Resumo
O presente artigo foi realizado a partir de uma pesquisa sobre um programa de TV de tipo mass media. Do ponto de vista teórico-metodológico, utilizaram-se as categorias de consciência possível e criação cultural de Lucien Goldmann para verificar como o discurso sobre saúde e estilo de vida está sendo veiculado nas falas de apresentadores e convidados. Os principais resultados mostraram um eixo norteador de direcionamento discursivo para determinação de comportamentos sociais e, ao mesmo tempo, antagonismo às características da consciência possível e da criação cultural da população que assiste a tal programa de TV.

Palavras-chave: Comportamentos saudáveis. Cultura. Comportamento social.
\end{abstract}

\section{THE HEALTH DISCOURSE IN THE "BEM ESTAR" PROGRAM BASED ON POSSIBLE CONSCIOUSNESS AND CULTURAL CREATION}

\begin{abstract}
This article was based on a research on a mass media TV program. From the theoretical and methodological point of view, Lucien Goldmann's categories of possible consciousness and cultural creation were used to verify how the discourse on health and lifestyle is being conveyed in the speeches of presenters and guests in the TV show. The main results showed a guiding axis of discursive direction for determination of social behaviors and, at the same time, antagonism to the characteristics of the possible consciousness and the cultural creation of the population that attends such TV program.
\end{abstract}

Keywords: Health Behavior. Culture. Social Behavior.

\section{EL DISCURSO SOBRE SALUD EN EL PROGRAMA “BEM ESTAR" A PARTIR DE LAS CATEGORÍAS DE CONCIENCIA POSIBLE Y CREACIÓN CULTURAL}

\section{Resumo}

El presente artículo se realizó a partir de una investigación sobre un programa televisivo de tipo mass media. Desde el punto de vista teórico-metodológico, se utilizaron las categorías de conciencia posible y creación cultural de Lucien Goldmann. El uso de esas categorías nos permitió verificar cómo el discurso sobre salud y estilo de vida está siendo vehiculado en las 
conversaciones entre presentadores e invitados. Los principales resultados mostraron un eje orientador de direccionamiento discursivo para la determinación de comportamientos sociales y, al mismo tiempo, antagonismo sobre las características de la conciencia posible y sobre la creación cultural de la población que asiste a tal programa televisivo.

Palabras clave: Conductas Saludables. Cultura. Conducta Social.

\section{Introdução $^{1}$}

Entender a velocidade de informação que vem sendo imposta na vida dos cidadãos é estar atento à propagação de notícias que as mídias apresentam, tanto os meios de comunicação de massa representados pelo rádio, pela televisão, pelo jornal e pela revista quanto as tecnologias de informação/comunicação, tendo como forte expoente a internet (DACOSTA; BETTI, 2006). No entanto, para Pires et al. (2008), somente a partir dos anos 1990 surge o interesse acadêmico da área da Educação Física (EF) sobre os meios de comunicação, reconhecendo a importância da informação tecnologicamente mediada sobre temas próprios dessa área, como o corpo, o esporte e o movimento.

Para divulgar o que vem a ser saúde, a mídia utiliza-se em boa parte do discurso veiculado de informações sobre o corpo. Nos espaços preestabelecidos, considerados saudáveis ou que tentam proporcionar saúde, são remetidas imagens, repetidamente, de corpos-modelo que transpiram saúde e beleza e são reflexos diretos das divulgações midiáticas. A mídia e as relações de consumo formatam um ambiente propício ao consumo do corpo, aludindo a um panorama que remete, em última instância, à venda de um estilo de vida saudável (COSTA; VENÂNCIO, 2004).

Outra forma de promover uma boa saúde pela mediação das mídias é o uso desmedido dos fatores de risco associados ao corpo. Através de cálculos matemáticos, ratifica-se a busca pelo controle da vida e pelos benefícios que a prática de atividade física instaura na saúde dos indivíduos, com o escopo de diminuir a probabilidade do surgimento dos fatores de risco de doenças crônico-degenerativas. Vale lembrar, entretanto, que a saúde é regulada em grande parte pela economia de mercado, no qual destaca-se a comercialização de cosméticos, fármacos e produtos alimentícios, que serviriam para a aquisição de um estado ótimo de saúde (PALMA et al., 2010).

Referente à relação saúde e atividade física, Alves e Carvalho (2010) destacam o discurso ideológico da mídia, que dita padrões estéticos de beleza e saúde pela reprodução de uma representação do ser saudável. Nessa perspectiva, as imagens incutidas pelas mídias - de modo a serem vistas como modelo de um corpo saudável - conduziriam as pessoas a confrontarem-se diariamente com os cuidados essenciais para ter uma boa saúde.

Nesse sentido, é importante frisar, como ressalta Neira et al. (2008), que o controle simbólico é um instrumento que se apresenta nas instituições sociais e está em constante mobilidade, interferindo nos sujeitos pelas relações sociais, ou seja, na construção dos sujeitos e das subjetividades. Nesse sentido, mas em outra perspectiva, Vendrúscolo, Malina e Azevedo (2014) mostram que a mídia traria um potente aparato discursivo ideológico que contribuiria para a divulgação de ideias e valores dominantes.

Por considerar a televisão um meio de comunicação midiática presente e expressivo na formação da consciência e do conhecimento dos sujeitos, a presente pesquisa investiga como são as narrativas de promoção da saúde e de estilos de vida veiculadas em um programa de televisão. O objetivo é contribuir para compreender os interesses e fundamentações presentes

\footnotetext{
${ }^{1} \mathrm{O}$ presente trabalho não contou com apoio financeiro de nenhuma natureza para sua realização.
} 
na comunicação feita pelas mídias, por considerá-las intermediárias no acesso às informações e aos conhecimentos referentes à saúde e à consequente influência na formação social.

\section{Aspectos metodológicos}

Com vistas a alcançar o objetivo acima delineado, selecionou-se para investigação o programa Bem estar, da Rede Globo de Televisão, transmitido de segunda a sexta-feira, no período da manhã. O programa Bem estar entrou na programação da emissora Rede Globo no dia 21 de fevereiro de 2011 e mantém o mesmo formato até os dias atuais, com o objetivo de divulgar informações sobre saúde e qualidade de vida. Para tanto, conta com uma pauta de assuntos sobre cuidados com o corpo; alimentação; ambiente doméstico, do trabalho e do lazer etc. A equipe do programa Bem estar é formada por jornalistas, acompanhados da presença de especialistas da área médica que dão suporte teórico e prático às discussões que são destaques nas pautas da programação.

Desse modo, para a análise na presente pesquisa, foram selecionadas, aleatoriamente, cinco edições do programa Bem estar, exibidas no ano de $2014 .^{2}$ A análise dessas edições foi realizada ao longo de 2015 e 2016 - daí as edições serem datadas do ano de 2014 - porque consideramos necessário assistir às edições repetidas vezes, de forma a permitir retornar às questões consideradas importantes e destacadas para análise.

A seleção das edições deu-se por meio do banco de dados disponível no próprio endereço eletrônico http://g1.globo.com/bemestar/index.html, da Globo Comunicações e Participações S.A., destinado ao programa Bem estar. As cinco edições ilustrativas selecionadas para a análise trazem as seguintes pautas:

1. vida moderna e saúde, do dia 3/11/2014;

2. a relação de dores de cabeça com problemas cardíacos, do dia 28/10/2014;

3. dieta saudável, do dia 27/10/2014;

4. a dança e seus benefícios à saúde, do dia 7/11/2014;

5. dores nas articulações e quais os benefícios que a reeducação postural e o alongamento podem produzir na diminuição ou na anulação desses incômodos, do dia 10/11/2014.

A partir dos dados levantados, a análise consistiu em identificar:

a) a concepção do que é saúde, a partir da fala dos especialistas e dos indivíduos envolvidos;

b) quais as associações com outras temáticas;

c) quais são as pessoas que participam do debate em questão.

Como referencial teórico para inspirar tal análise, utilizaram-se as categorias consciência possível e criação cultural, do sociólogo Lucien Goldmann (1979; 1977). ${ }^{3}$ De forma sintética, pode-se dizer que a consciência possível é decorrente de um contraste com a consciência real e reforça uma teleologia orientada por pressupostos de circunstâncias históricas determinadas, nas quais um grupo ou uma classe social supera a consciência real (que está sendo permanentemente reificada no sentido marxista), sem necessariamente conseguir modificar o sistema sociopolítico vigente, mas modificando a orientação teórica ou teórico-prática de uma questão. Pode ser um exemplo de máximo de consciência possível a busca dos escravos por liberdade ou ainda a consciência possível pode estar presente em

\footnotetext{
2 Não houve quaisquer conflitos de interesse no desenvolvimento da presente pesquisa.

${ }^{3}$ Filósofo e sociólogo marxista nascido na Romênia e radicado na França, orientado por Jean Piaget, e influenciado por Kant, Pascal e Racine e, especialmente, Marx. Teve como um de seus "discípulos" Michel Löwy.
} 
questões mais específicas, sempre em acordo com a libertação de certas circunstâncias históricas aprisionadoras.

Já a criação cultural refere-se a quando um grupo ou uma classe social materializa uma expressão desse grupo ou dessa classe, encontrando reverberação na sociedade por meio da cultura. Daí decorre uma tensão que permeia as classes sociais, por meio de um reforçamento da consciência real, por exemplo por intermédio de aparatos culturais ou de comunicação de classe reificadores versus as possibilidades de criação cultural e do alcance do máximo de consciência possível da classe trabalhadora. Dessa forma, a criação cultural pode potencializar uma força de conscientização para superar a consciência real em direção à consciência possível.

\section{Análise dos dados}

A edição do programa Bem estar sobre o tema vida moderna e saúde, do dia 3/11/2014, aborda as transformações e praticidades dos novos tempos, proporcionados pela evolução da tecnologia e da ciência. A finalidade dessa edição é responder aos desafios desse período. Partindo do pressuposto dos benefícios da atividade física, o programa alerta ao público sobre as diferenças que os aparatos tecnológicos contemporâneos ocasionam na saúde da população, à medida que proporcionam hábitos e comportamentos que não favorecem a "queima" de calorias. Desse modo, inicialmente destaca-se a fala do professor de Educação Física sobre a distinção entre se movimentar e ficar parado:

Esse é o segredo, gastar mais calorias, você tem que mover mais músculos, sair do estado de repouso, que é o grande problema. O simples fato de você ficar em pé, os músculos posturais já solicitam um maior gasto calórico. Se você está sentado, fique em pé; parado, caminhe, é muito melhor. (BEM ESTAR, 3/11/2014).

Em seguida, a apresentadora reforça: "Dica primeira de hoje, dica do Bem estar: se tá sentado, fica em pé, assista a gente em pé". Na continuidade do programa, foi feita uma pergunta ao público, com a intenção de saber o que o indivíduo faz quando vai estacionar o carro no estacionamento do shopping, questionando o seguinte: Quando vai ao shopping, você: 1) para na primeira vaga que encontra; 2) dirige até achar um lugar perto da entrada; 3) para longe da entrada e faz uma caminhada. Dentre as três opções, a terceira opção teve 10\%, acompanhada de $40 \%$ da segunda e $50 \%$ da primeira. Em seguida à divulgação do resultado, um professor de Educação Física comenta: "Isso é um comportamento muito comum, as pessoas gostam de economizar energia, economizar é dinheiro. Você tem que gastar energia acumulada. É o famoso débito calórico".

Em outro questionamento dirigido ao público, é perguntado: Quando você precisa subir dois andares, você: 1) vai pela escada; 2) espera em pé o elevador; 3) se for possível, senta e espera o elevador. Nesta segunda pergunta, a terceira opção teve $12 \%$, a segunda $32 \%$ e a primeira 56\%. Após a exposição do resultado, a médica consultora do programa diz:

Olha aí, quem assiste o Bem estar tá bem, porque até agora está indo muito bem, tá gastando energia, é isso aí, são pequenos momentos da vida que a gente pode aproveitar pra gastar um pouquinho mais de calorias. (BEM ESTAR, 3/11/2014).

Com a ideia de gasto calórico, todavia, o programa leva a discussão para um sentido mais restrito do que venha a ser promoção da saúde. As principais vias de conhecimento que se estabelecem são da área biomédica, as quais enfatizam alternativas e atitudes que possam repercutir em respostas que levem o indivíduo a gastar as devidas calorias, com vistas a alcançarem um nível adequado de saúde. 
Dessa forma, observando as duas perguntas e as respostas mais escolhidas pelas pessoas, pode-se considerar que o modo de vida fugaz das metrópoles interfere nas atitudes cotidianas dos sujeitos, que buscam sempre alternativas práticas, sem considerar a questão do discurso sobre saúde veiculado pelo programa de televisão.

Posteriormente, relacionando modernidade tecnológica com trabalho, o programa exibe uma reportagem a respeito das condições dos pedreiros. O que é posto em primazia é a diminuição do trabalho manual, em detrimento do trabalho das máquinas, o que ocasiona, segundo o programa, um aumento no percentual de indivíduos acima do peso e com obesidade. Com a finalidade de saber quais são os aspectos que influenciam esse quadro, o repórter realiza a pergunta a uma especialista: "O fato das máquinas terem substituído muito dos trabalhos mais pesados, isso pode ter influenciado pra essa mudança de quadro?". A nutricionista, de pronto, responde: "É um dos fatores também que deve ser levado em consideração, faz menos esforços com as atividades da obra, por conta dessa substituição de máquinas". De imediato, a reportagem procura se inteirar sobre a alimentação dos trabalhadores, na qual novamente a especialista se posiciona:

O que a gente constata também é com relação aos embutidos, linguiça ou a carne de porco, fontes de gordura saturada, e a falta, realmente, dos alimentos mais saudáveis, em termos de salada, de verduras, de legumes. (BEM ESTAR, $03 / 11 / 2014)$

Nota-se que as respostas que são apresentadas partem dos conhecimentos do campo da nutrição para revelar as condições de saúde dos trabalhadores. Simultaneamente, os discursos estão em conformidade com a tese do aumento dos gastos calóricos, o que gera uma tendência às ideias sobre o aumento de atividade física. Além disso, deve ser considerado o tipo de refeição que o trabalhador consome no seu tempo de serviço, bem como a ideia do programa parece instaurar a importância, a necessidade e o prazer do trabalho manual na construção de edifícios.

O contexto em que as pessoas vivem, contudo, não é incluído no debate. Isto é, a organização social em que vivem disponibiliza meios para ser praticada atividade física constantemente e de forma prazerosa? Ou, ainda, será que as próprias condições concretas da realidade e, consequentemente, da cultura local não influenciam na escolha dos sujeitos em não realizar práticas corporais? Por fim, pensar as preferências alimentares desse grupo social isoladamente torna ser o certo a ingestão de uma alimentação equilibrada em nutrientes?

Nesse mesmo capítulo, o programa busca averiguar a relação da modernidade com o trabalho no campo. O que se constata é a diferença da alimentação dos trabalhadores do campo, tendo a presença maior de legumes e verduras, com a refeição dos pedreiros. Visto dessa maneira, os agricultores respondem aos motivos que levaram à reeducação alimentar do grupo, e o chefe deles diz:

Hoje as pessoas estão aprendendo a se reeducar alimentarmente, a medicina evoluiu e esse lado aí nos mostra o quanto é importante tudo que você tem que comer, pra ter boa saúde e bom rendimento. (BEM ESTAR, 03/11/2014)

Em seguida, um dos agricultores fala: "O dia que a gente precisa de energia pra trabalhar o dia todo, com essa alimentação a gente trabalha tranquilo, sem problema nenhum, não sente aquela vontade de tá comendo o dia todo". Com Goldmann (1977), pode-se dizer que, nos trechos acima explicitados, a reificação está sendo processada a partir do simples reflexo das consciências do grupo social, que os afastam da essência da produção da existência do homem, naturalizando as relações sociais. 
Observa-se também o discurso do professor de Educação Física na relação do homem com a modernidade no seu cotidiano: "Veja um detalhe interessante, os braços das pessoas estão afinando e as pernas, é muito interessante a mudança na estrutura corporal [...]. Nós vamos ter um novo tipo de homem". Analisando esta fala, pode ser percebido que o homem está subordinado ao sistema social, devendo priorizar a manutenção desse avanço tecnológico e os interesses que regem esse arranjo social, não cabendo ao homem intervir em sua realidade na busca de mudanças, mas procurar se adaptar ao modo de vida determinado externamente, como é explicitado nas diversas citações sobre alimentação e exercício físico durante o programa.

Já a edição de 28/10/2014 trata da relação de dores de cabeça com problemas cardíacos e mostra como um projeto de pesquisa da Universidade de São Paulo (USP), dedicado ao estudo de atividades no meio líquido com água aquecida, pode contribuir na redução do quadro de hipertensão dos indivíduos.

Isto posto, o programa exibe como o projeto de pesquisa influenciou na mudança de hábitos de uma das voluntárias, ilustrado pela dedicação dela na prática de atividade física dentro de sua própria residência, adaptando o espaço para a realização de circuitos de caminhada, corrida, subida e descida de escada. Terminada a matéria, imediatamente o especialista no estúdio ressalta:

Como sempre disse, exercício, exercício e exercício, quer dizer, é o elixir da vida, fazer exercício na piscina com água quente, água salgada, água doce não interessa [...] é o que aconteceu, ela entrou no programa num protocolo científico e estimulou ela fazer exercícios em casa, subir e descer escada, então é fazer exercício, ajuda a baixar a pressão. (BEM ESTAR, 28/10/2104).

Observa-se, no discurso do especialista e na forma como é editado o programa, a construção do estado de dependência dos sujeitos ouvintes com relação à prática de atividade física e com as orientações de um especialista médico na condução de se ter uma boa saúde, estabelecendo um sentido de discurso inquestionável. Visto dessa maneira, o que pode ser criado nesse contexto é uma redução da capacidade de criação cultural - no sentido de Goldmann (1979; 1977) e corroborado por Frederico (2012) - do coletivo que assiste ao programa, uma vez que os indivíduos devem seguir minuciosamente as prescrições apresentadas, o que influencia atitudes com objetivos imediatos, motivados somente pelo controle da enfermidade e pela inserção temporária num programa de pesquisa.

$\mathrm{Na}$ edição do programa Bem estar do dia 27/10/2014, o tema abordado foi sobre dieta saudável. Neste capítulo, foi contada a trajetória de um rapaz chamado Bruno, que participa da coluna \#euresisti, ${ }^{4}$ mostrando os erros e os acertos no decorrer de sua participação nesse quadro. O objetivo do participante, com sua entrada no programa, era o seguinte, segundo seus argumentos: "Sou novo e tinha certeza que poderia mudar de vida, o que eu queria era voltar a ter o corpo que eu tinha antes de começar a trabalhar; o corpo e a disposição".

Os especialistas, um médico do esporte e uma nutricionista, então, passam a analisar o cotidiano do participante, especialmente o tempo e o espaço de trabalho. A partir das opções e quantidades colocadas de líquidos e alimentos no estúdio do programa, o médico especialista argumenta pela escolha de quantidades excessivas de líquido pelo participante:

Ele usa o momento das refeições para se hidratar, então, ele fica trabalhando na manhã, na tarde, aí a hora que ele senta na mesa é aquele momento que não só se alimenta como se hidrata, então ele procura sempre grandes quantidades e pela

\footnotetext{
4 \#euresisti é uma campanha feita pelo programa com vistas à mudança de estilo de vida individual através do controle da saciedade alimentar.
} 
associação refeição, falta de hidratação ao longo do dia, ele acaba consumindo grande quantidade. (BEM ESTAR, 27/10/2014).

Por outro lado, de acordo com o participante, sua escolha também se deve à não abundância de água no local do trabalho, pois a legislação determina que não pode ter alimentos e bebidas e diz: "A gente fica meio que sem poder se alimentar e beber conforme a nossa rotina aí”. Logo, a emissão das informações dá conta de estabelecer uma certa ordem na estrutura de produção social atual, pois as informações que são repassadas, tanto ao participante do quadro \#euresisti quanto ao público que acompanha as transmissões do programa, são direcionadas à manutenção da ordem.

Nessa mesma edição do programa, é apresentado o processo de estresse que o participante vem sofrendo. Logo, o que se destaca são os mecanismos biológicos acionados com o aparecimento da doença. Sabe-se, entretanto, que as causas de sua manifestação em grande medida são sociais, mas o programa não coloca em discussão esse aspecto. Por conseguinte, o estresse está associado ao aumento da produção do hormônio cortisol, o que pode estar relacionado com os ganhos de gordura, a perda de massa muscular e a resistência à insulina, provocando modificações no biótipo dos indivíduos. Assim, a apresentadora interroga o especialista sobre qual a dica para as pessoas reduzirem o estresse e, imediatamente, a resposta é a prática de atividade física.

Neste sentido, conforme Goldmann (1979) e Frederico (2006), os obstáculos junto à transmissão das informações são perceptíveis nas edições do programa. O processo de mudança de consciência real para a consciência possível da classe trabalhadora é dificultado pela ausência de informações prévias com relação aos fatores desencadeadores do processo de estresse. Nesse momento, dificultam-se possíveis mudanças da consciência real, no programa representada pela busca da alimentação balanceada e da prática de exercícios físicos. O que se constata é a defesa de argumentos que geram a ideia de promoção da saúde, sem dar conta da transformação da consciência trabalhadora na superação de sua condição desigual no interior do sistema capitalista.

A edição do dia 7/11/2014 do programa Bem estar versa sobre a dança e seus benefícios à saúde. Durante o programa, é possível observar os discursos do especialista da área médica sobre a importância de praticar essa expressão corporal, pois os seus variados tipos influenciam no desenvolvimento de musculaturas específicas, na recuperação de doenças, na coordenação motora, tal como no auxílio do funcionamento cardíaco otimizado. Por ora, todas as intervenções do especialista são condicionadas pela base de conhecimento fisiológico e anatômico.

Procurando saber como a dança pode ser trabalhada no âmbito educacional formal, o programa expõe um grupo de dança no interior de uma escola, onde os objetivos estão de acordo com os temas biológicos mencionados acima. O professor de dança da escola acrescenta ainda: "Elas [pessoas] podem, que elas são bonitas, que elas são felizes, que depois daquela aula elas vão ficar mais felizes ainda, trabalho de autoestima, de valorização pessoal". Em seguida, o repórter busca saber opiniões sobre a iniciativa do grupo de dança, e a professora do colégio responde: "É inovador, principalmente pra Educação Física, que hoje em dia precisa de novos incentivos e tudo que provoca bem-estar nós estamos dentro, com certeza". Retornando ao estúdio, a apresentadora argumenta e pergunta: "A dança pode ser um estímulo, por exemplo, pra atividade física e pra Educação Física nas escolas, que é uma coisa que a gente acha e sente que tá precisando se renovar né?" Em seguida, a especialista completa:

Exatamente nessa fase da infância, que é quando a gente ganha as capacidades e habilidades, que a gente vai levar pra vida inteira né, que é a capacidade motora, 
ganha musculatura, melhora a massa óssea [...] então foi muito bacana essa frase que ela disse, realmente, é um estímulo interessante. (BEM ESTAR, 7/11/2014).

Observa-se que há um distanciamento dos discursos acima com o papel da dança como conteúdo pedagógico. Da forma como foi mediada pelo grupo de dança, o propósito da aula passa a ser o divertimento, estando mais próximo de um tempo e espaço recreacionais. Desse modo, almejar uma imediata felicidade, apoiada numa espécie de hedonismo momentâneo, não parece ser a fórmula ideal para o bem-estar ao longo da vida. Para satisfazer as necessidades humanas, não é preciso somente participar de um momento motivacional ou reproduzir, incessantemente, modos de se movimentar sem incentivar uma reflexão sobre sua prática. Parece ser interessante, ao contrário, possibilitar outras finalidades e sentidos para a atividade realizada. Na perspectiva mostrada pelo programa, a dança perde seu potencial de criação cultural quando projetada apenas para fim de diversão e ganhos fisiológicos, o que provoca o desarranjo de seus significados e valores partilhados por seus entes e, por conseguinte, há uma diminuição no nível de consciência dos sujeitos.

$\mathrm{Na}$ tiragem do programa do dia 10/11/2014, o tema é sobre dores nas articulações e quais os benefícios que a reeducação postural e o alongamento podem produzir na diminuição ou na anulação desses incômodos. Atenta ao início do programa, uma telespectadora faz a seguinte pergunta: "Trabalho o dia inteiro sentada e sinto muita dor nas costas. Por que isso acontece?" O apresentador em seguida argumenta: "Olha, Leticia, você não tá sozinha nessa turma não. $80 \%$ da população do mundo já teve ou vai ter um dia dor nas costas, motivo também da nossa enquete de hoje". E, de imediato, é lançada a pergunta aos telespectadores: "Se você trabalha o dia todo sentado, você: 1) quase nunca levanta; 2) levanta só para ir ao banheiro; 3) faz algumas pausas ao longo do dia". Ao final, a primeira opção teve $13 \%$, a segunda $45 \%$ e a terceira $42 \%$. Após a divulgação, perguntado sobre o resultado, o especialista diz:

Esse resultado mostra que as pessoas não estão cuidando bem da sua musculatura e de suas articulações [...] o ideal é que pelo menos a cada 50 minutos a pessoa mude de posição, mude sua postura, levante; levantar e ir ao banheiro é bom, a pessoa aproveita vai ao banheiro, toma água, se hidrata e melhora um pouquinho a postura [...] e consegue levar melhor o dia com menos dor. (BEM ESTAR, 10/11/2014).

O que se percebe, no decorrer desse contexto do programa, é a falta de resposta com relação às causas que geram o desconforto na telespectadora e o direcionamento do debate numa forma de alento e conformismo, uma vez que o apresentador reforça e destaca que grande parcela da população é acometida por dores nas costas, provocando uma aceitação por parte daqueles que seguem o programa, pois muitos estão na mesma condição. Logo, precisam se conformar e estar integrados à ordem social. Dessa maneira, o discurso do especialista corrobora para o afastamento dos condicionantes sociais, transferindo unicamente a responsabilidade do estado de saúde dos trabalhadores para o próprio sujeito e desenvolvendo uma culpabilização da vítima. Dessa maneira, como é orientado por Goldmann (1979; 1977), terão dificuldades em compreender o real contexto em que estão inseridos, diminuindo as condições de criação cultural e provocando uma condição de reificação dos sujeitos.

Associado a esses fatores, o programa também divulga o tratamento de Reeducação Postural Global (RPG) e faz experiência com ele, como indicação para suportar e atenuar os impactos do desconforto que os trabalhadores vivenciam. Nesse trecho, os sujeitos são interpretados como mercadoria em troca dos serviços fisioterápicos, criando uma dependência de troca entre os trabalhadores e os métodos de correção postural, no qual se transfere uma certa autonomia do produto, RPG, sobre os sujeitos envolvidos no processo. Vale refletir se as 
próprias despesas ligadas ao RPG são economicamente elevadas, isto reforça a retirada completa da autonomia do sujeito e provoca uma contemplação diante da (im)provável solução do seu problema.

Frederico (2005) também alerta que a criação cultural está no âmago da autonomia, constituída pela coerência do máximo de consciência possível do coletivo, no qual seu objetivo é dar conta do esclarecimento da vida real, de forma que haja uma antecipação da consciência com relação aos acontecimentos. Visto assim, a criação cultural deve ser concebida, precipuamente, por meio das atitudes e ações dos indivíduos, pois, nessa perspectiva, a reflexão alcançaria a real existência do grupo, ultrapassando a ótica da saúde que é veiculada pelo programa, na qual o sujeito é tratado como mercadoria, estando determinado pelo consumo. Ultrapassar essa visão é estar mais próximo do máximo de coerência e do máximo de consciência possível, possibilitando a criação cultural de forma mais autônoma.

Nesse sentido, como finalização da análise, cabe discutir sobre quais as motivações que levam a própria emissora Rede Globo a intervir no tema da saúde, especificamente na construção de hábitos alimentares e de exercícios físicos que supostamente iriam assegurar uma possível ação preventiva ou reabilitadora em um suposto caso de enfermidade, assim como com as informações sobre doenças específicas e de higiene. Por outro lado, apesar de haver um espaço de participação dos telespectadores, o que se demonstra é a seleção de modo antecipado dos seus questionamentos no sentido de estarem em convergência com os eixos que norteiam as discussões alavancadas no programa. Ao contrário, questões que tocariam nos aspectos históricos e sociais, oferecendo mínimos momentos de reflexão sobre as condições reais de vida dos cidadãos, não são difundidas e discutidas durante os programas.

\section{Considerações finais}

Por meio das edições analisadas do programa Bem estar, da Rede Globo, pôde ser observada uma aproximação com a visão de promoção da saúde que prioriza as mudanças de comportamento e estilo de vida do indivíduo, levando em consideração conhecimentos da área biomédica que defendem a prática de atividade física, escolha de refeições equilibradas e, sempre que houver alguma anormalidade no estado de saúde, a procura de um médico com urgência. Sendo assim, seus discursos se formam dentro de uma visão medicalizada e, ao mesmo tempo, colocam toda a responsabilidade das condições de saúde nos indivíduos, visto que a autonomia dos telespectadores é reduzida pela dependência das orientações dos especialistas.

O entendimento de saúde veiculado pelo programa diminui a compreensão desse fenômeno, dando uma falsa sensação de que, buscando seguir as dicas e informações transmitidas aos ouvintes, a qualidade de vida será alcançada. Uma vez que os condicionantes históricos e sociais são negligenciados, parte-se do pressuposto de que as condições de vida são iguais para todos. Nesse sentido, as preocupações centrais do programa dão conta de uma visão de promoção da saúde reduzida, fazendo com que o poder de autonomia das pessoas seja limitado, na medida em que as informações não são apresentadas de maneira coerente com a realidade de vida da classe trabalhadora.

Dessa maneira, a forma e os discursos de promoção da saúde que o programa Bem estar defende mostram uma visão convergente para o conceito de prevenção, ilustrado pelos modos de vida propagados sobre o esforço das pessoas em se dedicarem às dicas que promoverão uma série de benefícios orgânicos, com o propósito de evitar ou aliviar certos agravos das condições de saúde. Logo, as orientações consistem no viés da mudança de comportamentos e de estilos de vida dos indivíduos a partir das fundamentações científicas. Estas são propostas através dos modelos dedicados ao estudo da biomedicina como resposta 
para melhorar a qualidade de vida das pessoas. As normas a serem seguidas, portanto, devem obedecer aos conhecimentos médicos que, oferecidos nessa perspectiva, podem provocar uma reificação e um conformismo desses grupos sociais, bem como um distanciamento da real e concreta condição de suas vidas.

Ressalte-se ainda que há um contraste entre os objetivos de normatização social do programa de televisão analisado e a dinâmica de vida dos entrevistados, mostrando uma desconexão. A proliferação de programas de televisão dessa natureza pode, no entanto, indicar um sucesso na audiência do programa e/ou na influência sobre os comportamentos sociais de quem assiste a eles, antagonizando as possibilidades da consciência possível e da criação cultural e aprofundando a reificação em tempos atuais.

\section{Referências}

ALVES, F. S.; CARVALHO, Y. M. Práticas corporais e grande saúde: um encontro possível. Revista Movimento, Porto Alegre, v. 16, n. 4, p. 229-244, out. /dez. 2010.

BEM ESTAR. Rede Globo de Televisão. 27 out. 2014. Disponível em: <http://g1.globo.com/bemestar/videos/t/edicoes/v/bem-estar-edicao-de-segunda-feira27102014/3723943/>. Acesso em: 4 nov. 2014.

Rede Globo de Televisão. 28 out. 2014. Disponível em: <http://g1.globo.com/bemestar/videos/t/edicoes/v/bem-estar-edicao-de-terca-feira28102014/3725904/>. Acesso em: 6 nov. 2014.

Rede Globo de Televisão. 3 nov. 2014. Disponível em: <http://g1.globo.com/bemestar/videos/t/edicoes/v/bem-estar-edicao-de-segunda-feira03112014/3738725/>. Acesso em: 7 nov. 2014.

Rede Globo de Televisão. 7 nov. 2014. Disponível em: <http://g1.globo.com/bemestar/videos/t/edicoes/v/bem-estar-edicao-de-sexta-feira07112014/3749298/>. Acesso em: 11 nov. 2014.

Rede Globo de Televisão. 10 nov. 2014. Disponível em: <http://g1.globo.com/bemestar/videos/t/edicoes/v/bem-estar-edicao-de-segunda-feira10112014/3754476/>. Acesso em: 14 nov. 2014.

COSTA, E. M. de B.; VENÂNCIO, S. Atividade física e saúde: discursos que controlam o corpo. Revista Pensar a Prática, v. 7, n. 1, p. 59-74, mar. 2004.

DA COSTA, A. Q.; BETTI, M. Mídias e jogos: do virtual para uma experiência corporal educativa. Revista Brasileira de Ciências do Esporte, Campinas, v. 27, n. 2, p. 165-178, jan. 2006.

FREDERICO, C. A Sociologia da Literatura de Lucien Goldmann. Estudos Avançados, São Paulo, n. 19, v. 54, 2005, p. 429-446. 
. Sociologia da cultura: Lucien Goldmann e os debates do século XX. São Paulo: Cortez, 2006. p. 86-126.

. Quem fala na criação cultural? Notas sobre Lucien Goldmann. Revista Matrizes, São Paulo, ano 5, n. 2, p. 181-194, jan./jun. 2012.

GOLDMANN, L. Ciências Humanas e Filosofia: o que é a Sociologia? 7. ed. Rio de Janeiro: Difel, 1979.

Sociologia e sociedade: leituras de introdução à sociologia. In: GOLDMANN, L. A reificação das relações humanas. Rio de Janeiro: LTC, 1977. p. 137-146.

NEIRA, M. G. et al. Mídia e futebol: contribuições para a construção de uma pedagogia crítica. Revista Brasileira de Ciências do Esporte, Campinas, v. 30, n. 1, p. 91-106, set. 2008.

PALMA A. de O. et al. Culto ao corpo e exposição de produtos na mídia especializada em estática e saúde. Revista Movimento, Porto Alegre, v. 16, n. 1, p. 31-51, jan./mar. 2010.

PIRES, G. de L. et al. A pesquisa em educação física e mídia: pioneirismo, contribuições e críticas ao "Grupo de Santa Maria". Revista Movimento, Porto Alegre, v. 14, n. 3, p. 33-52, set./dez. 2008.

VENDRUSCOLO, M. F.; MALINA, A.; AZEVEDO, Â. C. B. de. A concepção de obesidade e padrão corporal por mediações ideológicas da mídia. Pensar a Prática, Goiânia, v. 17, n. 1, p. 503-516, jan./mar. 2014.

Recebido em: 27/01/2018

Revisado em: 28/05/2018

Aprovado em: 25/07/2018

Endereço para correspondência:

alancesar1987@hotmail.com

Alan Cesar Dantas Chaves Pombo

Secretaria Municipal De Educação

Av. Braz de Pina, 1614

Vista Alegre

21070-031 - Rio de Janeiro, RJ - Brasil 